\title{
The importance of education to increase the use of bed nets in villages outside of Kinshasa, Democratic Republic of the Congo
}

\author{
Julie K Ndjinga ${ }^{1,2}$, Noboru Minakawa ${ }^{*}$
}

\begin{abstract}
Background: Malaria is the most prominent disease in the Democratic Republic of the Congo (DRC), and longlasting insecticide-treated nets (LLINS) have been distributed free of charge since 2006 to combat the disease. However, the success of this bed net campaign depends on sufficient bed net use in all age groups. This study was designed to examine the factors affecting bed net use in villages outside of Kinshasa.

Methods: Two villages along the Congo River, totalling 142 households with 640 residents, were surveyed using a standard questionnaire. The interview determined the number, ages, and sexes of family members; the education level of the family head; the number, colour, and type of nets owned; and the number of nets used in the previous night. The size of house was also measured, and numbers of rooms and beds were recorded. These variables were examined to reveal important factors that affect bed net use.
\end{abstract}

Results: A total of 469 nets were counted, and nearly all nets were white LLINs. Of these nets, 229 (48.8\%) nets were used by $284(44.4 \%)$ residents. Bed nets were used by over $90 \%$ of children 5 to 15 years of age, whereas less than $50 \%$ of the residents in other age groups used bed nets. The important variables affecting bed net use were numbers of beds and rooms in the house and the education level of the family head of household.

Conclusion: Education was the most important factor affecting bed net use in the villages outside Kinshasa. Development of an educational programme, particularly one directed toward parents, is necessary to reduce misconceptions and increase prevalence of bed net use among all age groups.

\section{Background}

Malaria is one of the leading causes of morbidity and mortality in the Democratic Republic of the Congo (DRC), with approximately 180,000 deaths attributed to malaria each year [1]. This is one fifth of the 863,000 malaria deaths reported worldwide by the World Health Organization in 2008 [2]. The large number of malaria cases in the DRC is due to high malaria transmission rates, and it is exacerbated by two decades of civil war that have decimated the health care infrastructure and the government's ability to deliver social services.

Insecticide-treated bed nets offer essential protection against mosquitoes and significantly reduce morbidity

\footnotetext{
* Correspondence: minakawa@nagasaki-u.ac.jp

${ }^{2}$ Department of Vector Ecology and Environment, Institute of Tropical Medicine (NEKKEN) and the Global COE Program, Nagasaki University, 1-12-4 Sakamoto, Nagasaki, Nagasaki 852-8523, Japan

Full list of author information is available at the end of the article
}

and mortality due to malaria, particularly in endemic areas $[3,4]$. The DRC government distributed nearly 11.2 million long-lasting insecticide-treated nets (LLINs) free of charge between 2006 and 2008. This campaign provided LLINs to only $30 \%$ of the households and $24 \%$ of children younger than 5 years old [5]. To boost bed net coverage, the National Malaria Control Programme (NMCP) in the DRC planned to distribute an additional 2 million LLINs to cover at least 4 million people in Kinshasa and its surrounding villages in 2008.

Attempts to use bed nets are often hampered by environmental, social, and cultural considerations. Potential factors that affect bed net use are education level of family head, wealth, colour and shape of bed nets, house structure, sleeping arrangement, distance to retail stores and cultural taboos [6-9]. Even though LLINs have gained popularity, the effectiveness of LLINs against malaria transmission will be impaired without 
their proper use. Studies have shown that owning LLINs does not always increase the prevalence of use [10-13]. For instance, nets are occasionally misused for other purposes such as fishing in villages near Lake Victoria [14]. Little information is available about bed net use in the DRC, with the exception of a few studies on bed net use by women and children in Kinshasa before the mass distribution [15-17]. This study was designed to investigate availability and use of bed nets after the recent mass distribution in the villages outside Kinshasa and to determine the factors affecting bed net use.

\section{Methods}

\section{Study area}

A field survey was conducted in two villages, Mombele and Mbangu Mbangu, along the Congo River, outside of Kinshasa in October and November 2009 at the beginning of the rainy season. Mombele and Mbangu Mbangu are approximately $60 \mathrm{~km}$ and $90 \mathrm{~km}$ away from Kinshasa. Malaria is endemic in these villages, with stable transmission throughout the year. Plasmodium falciparum is responsible for the serious forms of malaria, with Anopheles gambiae as the main vector of transmission [18]. The major income sources in the villages are fishing and traditional small-scale farming. Bed nets have been distributed by a local health centre within each village through the recent program organized by NMCP.

\section{Data collection}

In total, 142 households with 640 residents were randomly selected, including 72 households in Mombele and 70 in Mbangu Mbangu. Oral informed consent to conduct interviews was obtained by the village chiefs and staff members of the Nsele District Department of Health. A responsible member of each household was interviewed in the local Lingala language using a standard questionnaire. Interviewees were asked the number, ages, and sexes of family members; the education level of the head of household; the number, colour, and type (LLIN or not) of nets they possessed; and the number of nets used in the previous night. They were also asked where the bed nets were obtained, and whether each family member had slept under a net either on a bed or on the floor the previous night. When any family members did not sleep under a net, interviewees were asked the most important reason for this choice. After the interview, the floor area $\left(\mathrm{m}^{2}\right)$ of each house was measured using a tape measure, and the numbers of rooms and beds were counted. The locations of beds and nets were also noted.

\section{Data analysis}

A generalized linear mixed model (GLMM) using the lme4 package in $\mathrm{R}$ with binomial distribution was used to examine whether bed net use was explained by residents age, sex, and village [19]. Two-way interaction terms were also included in the initial model. Age and sex were included in the initial model, because distributions of ITNs have been targeted to infants under 5 years of age and pregnant women [2]. As bed net use might differ between the villages, village was also included as a variable. Bed net use of each family member was a binary response variable defined as slept with or without a net. The backward selection procedure was modelled based on the Akaike Information Criteria and the log likelihood ratio test. Sampling dates were treated as a random intercept to consider variation between dates because the houses were surveyed on 16 separate dates. This modelling allowed for a random slope to find optimal random errors, if necessary.

The same modelling procedure was used to examine the relationships of bed net use at the household level with bed availability, bed net availability, house size, number of rooms, education level of head of household, and village as variables. Two-way interaction terms were also included in the initial model. Bed net use was a response variable defined as the ratio of the number of residents who slept with nets to the number of those who slept without nets in a house. The variables of bed availability, net availability, number of rooms and education level were included in the initial model, because past studies found that these variables affect bed net use [6-9]. As house size may affect bed availabily and number of rooms, this variable was also included. The variable of bed availability was defined as the total bed area $\left(\mathrm{m}^{2}\right)$ in a house, and house size was reported as total floor area $\left(\mathrm{m}^{2}\right)$. The values for these variables were divided by the adjusted number of residents in each house estimated based on body size: a child below 5 years of age was treated as 0.3 person, a child between 5 and 15 years of age as 0.5 person, and a person over 15 years of age as one person. The number of rooms in a house was not corrected for the number of residents because the qualitative characteristics of the rooms captured by the data might have been lost. For example, in a house with two or three rooms, one room was used as a living room and the others were usually used as bedrooms [9]. Using the raw number of rooms maintained both this characteristic and the quantitative characteristics. The education level was categorized by (1) incomplete primary education, (2) completed primary education, and (3) completed secondary or higher education.

\section{Results}

In total, 640 residents and 469 nets were counted with an average of 4.7 residents $(\mathrm{SD}=1.8)$ and 3.3 nets $(\mathrm{SD}=1.3)$ per house. Of the 469 nets, 229 (48.8\%) nets were used, and $284(44.4 \%)$ residents had slept under nets in the previous night (Table 1). Thus, 0.7 nets were available per 
Table 1 Numbers of residents who slept with nets and without nets

\begin{tabular}{lccc}
\hline & Slept with nets & Slept without nets & N \\
\hline Sex & & & \\
$\quad$ Female & $146(42.2 \%)$ & $200(57.8 \%)$ & 346 \\
$\quad$ Male & $138(46.9 \%)$ & $156(53.1 \%)$ & 294 \\
Village & & & \\
$\quad$ Mombele & $135(40.4 \%)$ & $199(59.6 \%)$ & 334 \\
$\quad$ Mbangu Mbangu & $149(48.7 \%)$ & $157(51.3 \%)$ & 306 \\
Total & $284(44.4 \%)$ & $356(55.6 \%)$ & 640 \\
\hline
\end{tabular}

resident, and 1.2 residents slept under a net. The mean size of houses was $17.2 \mathrm{~m}^{2}(\mathrm{SD}=5.0)$, and the mean number of rooms was $1.6(\mathrm{SD}=0.7)$ and of beds was $1.6(\mathrm{SD}=$ 0.7). Of 142 head of households, 51 (35.9\%) had not completed primary education, 43 (30.3\%) had completed primary education, and 48 (33.8\%) had completed secondary or higher education. Nearly all nets (468) were LLINs that were provided by the local health department free of charge and all nets were white.

The GLMM revealed that age was significantly associated with individual bed net use, but the variables of sex and village were not associated $(\mathrm{z}=-5.09, \mathrm{p}<$ 0.001 ). Bed nets were used by over $90 \%$ of children 5 to 15 years of age, whereas less than $50 \%$ of the residents in other age groups used bed nets (Figure 1).

Household bed net use was examined using six variables: bed availability, bed net availability, house size, number of rooms, head of household's education level, and village (Figure 2). The three variables of net availability, house size, and village were not included in the final model. Bed availability $(z=3.77, p<0.001)$, education level $(z=2.29, p=0.022)$, and number of rooms $(z=3.81, p<0.001)$ were significantly associated with bed net use at the household level. Net use was also significantly associated with the interaction between bed availability and the number of rooms $(z=-2.56, p=$ 0.011 ).

A total of 66 interviewees provided reasons why they did not use bed nets. The most common reason $(26$ cases, 39.4\%) was related to heat discomfort within a bed net. Twenty-two (33.3\%) respondents believed that females become infertile under a bed net. Two other reasons included associating bed net use with sleeping in a coffin (nine cases, 13.7\%) and the idea that the bed net campaign was a plot by the United States of America Central Intelligence Agency to reduce the African population by treating bed nets with a chemical that kills sleepers (eight cases, 12.1\%).

\section{Discussion}

The number of bed nets reported was enough to cover all the villagers, apparently a result of the recent NMCP campaign. Nevertheless, fewer than half of the nets were used, and half of the villagers did not sleep under the nets. A recent study reported that the prevalence of bed net use is $56 \%$ in Nigeria and over $90 \%$ in Senegal [10]. Thus, the proportion of nets used in the villages of the DRC is considerably lower compared with other African countries, and this may hamper the effectiveness of the malaria prevention campaign.

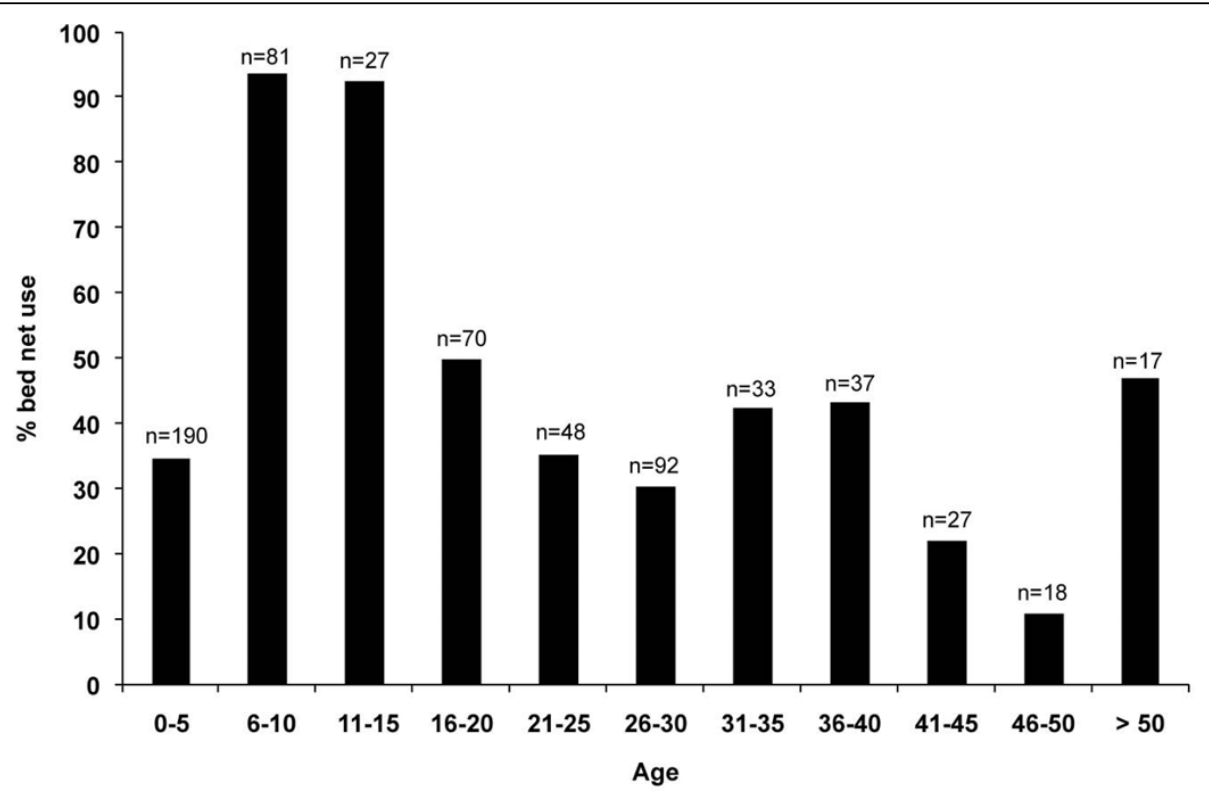

Figure 1 Percentages of bed net use among different age groups. 

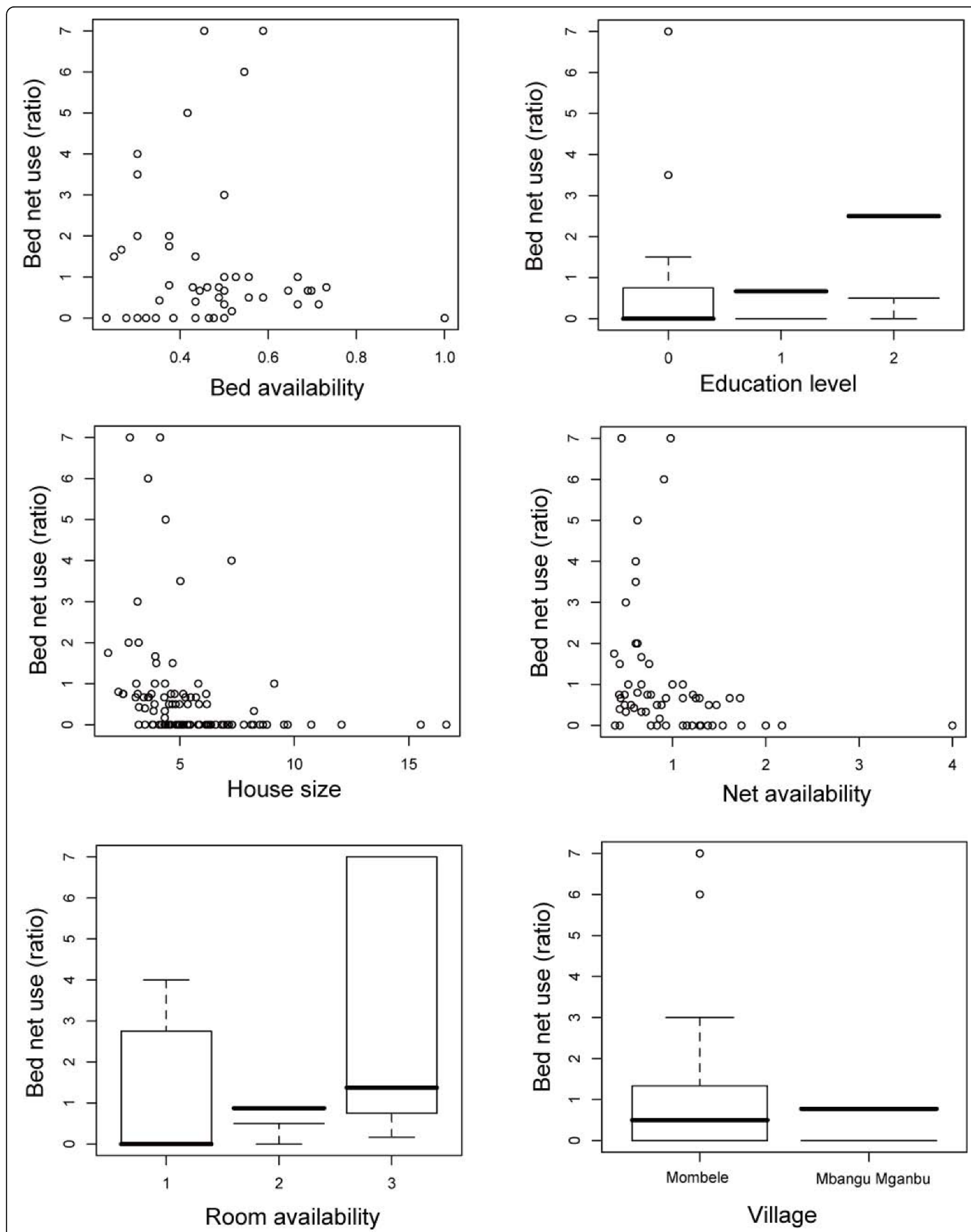

Figure 2 Relationships of bed net use with bed availability, education level of family head, house size, net availability, room availability and village. Bed net use was defined as the ratio of the number of residents who slept with nets to the number of those who slept without nets in a house. 
The most common reason given for not using bed nets was discomfort due to heat within the net. This reason was also common in other African countries $[6,10,20,21]$. The other reasons given were based on cultural myths, and failure to use bed nets is often associated with misconceptions and cultural taboos [22]. Discomfort due to the heat may also be a misconception; although the bed net may reduce airflow and increase temperature, the increase might not be noticeable, and if it is noticeable, one's health should not be comprised due to discomfort.

Education about malaria transmission and the benefits and proper use of bed nets should eliminate the misconceptions about bed nets usage. Results reported here demonstrate that the education level of the family head of household was associated with bed net use among family members in the surveyed villages. A previous study in Kinshasa also reported that women who had secondary school or higher education were 3.4 times more likely to own and 2.8 times more likely to use a bed net compared with women with less education [15]. A mother's education level and adequate knowledge about malaria transmission are also associated with their use of bed nets in other countries [21-23]. As a majority of children less than 5 years of age sleep with their parents in Africa, their protection from malaria depends on parents' perception of bed nets $[24,25]$.

This study also found a lower prevalence of net use among children less than 5 years of age and among adults, and a greater prevalence of use among school children 5 to 15 years old. This result was unexpected, as several studies have reported lower use of bed net use among school children $[9,21,25,26]$. Mothers and infants are primary targets for net distribution, and their use of nets should be high $[15,17]$. In recent years, primary and secondary schools have focused on education in disease prevention and sanitation, including bed net use in the district where the surveyed villages in this study are located. This systematic education program may explain the high prevalence of nets use among children 5 and 15 years of age in these villages.

The other important factors associated with bed net use were the numbers of beds and rooms in the house. These results are comparable to those from other studies $[21,27]$. As the number of rooms increased, the role of each room became clearer: it is common to use one room as a living room when a house has more than two rooms, and the others as bedrooms [9,27]. Residents who sleep on the floor in living rooms would have less attachment to nets compared with nets hung over beds in bedrooms, as the living room nets are most likely taken down every morning. Consequently, having more bedrooms increases both privacy and the space available for beds, which in turn increases the number of sites that are suitable for hanging nets, thereby increasing net use.

\section{Conclusion}

Assessed the reasons for not using bed nets, the greater use of nets among school children and the importance of education level of family head, it is evident that education was the most important factor affecting bed net use in the villages outside Kinshasa. Development of an educational programme, particularly one directed toward parents, is necessary to reduce misconceptions and increase prevalence of bed net use among all age groups.

\section{Acknowledgements}

The authors thank Dr. Hikaru Sato, Dr. Tomoko Abe, and Ms. Junko Sakemoto for facilitating this study. We also thank Oliver Tshiani, Jean Pierre Malemba, Ngunga Eddy, Devos, Jean-Marie, Celestin, Fabien, Jean Babu, Patrick, Agathe, and Kevin for assisting in the fieldwork. Finally, we thank all the study participants, who provided us with valuable information. This work was supported in part by the Japan International Cooperation Agency and the Global COE Program, Nagasaki University, Japan.

\section{Author details}

${ }^{1}$ Kinoise Clinic, AV.de La Justice N³6, Kinshasa, Democratic Republic of the Congo. ${ }^{2}$ Department of Vector Ecology and Environment, Institute of Tropical Medicine (NEKKEN) and the Global COE Program, Nagasaki University, 1-12-4 Sakamoto, Nagasaki, Nagasaki 852-8523, Japan.

\section{Authors' contributions}

JNK conducted the fieldwork and drafted the first manuscript. NM conceived the study and finalized the manuscript. Both authors have read and approved the final manuscript.

\section{Competing interests}

The authors declare that they have no competing interests.

Received: 17 April 2010 Accepted: 12 October 2010

Published: 12 October 2010

\section{References}

1. World Bank: Santé et Pauvreté en République Démocratique du Congo: Analyse et Cadre Stratégique de Lutte contre la Pauvreté. Africa Human Development Series. Washington D.C. 2005.

2. World Health Organization: World Malaria Report. Geneva 2009.

3. Lengeler $C$ : Insecticide-treated bed nets and curtains for preventing malaria. Cochrane Database Syst Rev 2004, CD000363.

4. Fegan GW, Noor AM, Akhwale WS, Cousens S, Snow RW: Effect of expanded insecticide-treated bednet coverage on child survival in rural Kenya: a longitudinal study. Lancet 2007, 370:1035-1039.

5. National Malaria Control Programme: Annual Report. Kinshasa 2009.

6. Alaii JA, Hawley WA, Kolczak MS, ter Kuile FO, Gimnig JE, Vulule JM, Odhacha A, Oloo AJ, Nahlen BL, Phillips-Howard PA: Factors affecting use of permethrin-treated bed nets during a randomized controlled trial in western Kenya. Am J Trop Med Hyg 2003, 68(4 Suppl):137-141.

7. Noor AM, Omumbo JA, Amin AA, Zurovac D, Snow RW: Wealth, mother's education and physical access as determinants of retail sector net use in rural Kenya. Malar J 2006, 5:5.

8. Ng'ang'a PN, Jayasinghe G, Kimani V, Shililu J, Kabutha C, Kabuage L, Githure J, Mutero C: Bed net use and associated factors in a rice farming community in Central Kenya. Malar J 2009, 8:64.

9. Iwashita H, Dida G, Futami K, Sonye G, Kaneko S, Horio M, Kawada H, Maekawa Y, Aoki Y, Minakawa N: Sleeping arrangement and house structure affect bed net use in villages along Lake Victoria. Malar J 2010, 9:176. 
10. Korenromp EL, Miller J, Cibulskis RE, Kabir Cham M, Alnwick D, Dye C: Monitoring mosquito net coverage for malaria control in Africa: possession vs. use by children under 5 years. Trop Med Int Health 2003, 8:693-703.

11. Baume CA, Marin MC: Intra-household mosquito net use in Ethiopia, Ghana, Mali, Nigeria, Senegal, and Zambia: are nets being used? Who in the household uses them? Am J Trop Med Hyg 2007, 77:963-971.

12. Thwing J, Hochberg N, Vanden Eng J, Issifi S, Eliades MJ, Minkoulou E, Wolkon A, Gado H, Ibrahim O, Newman RD, Lama M: Insecticide-treated net ownership and usage in Niger after a nationwide integrated campaign. Trop Med Int Health 2008, 13:827-834.

13. Baume CA, Reithinger $R$, Woldehanna S: Factors associated with use and non-use of mosquito nets owned in Oromia and Amhara regional states, Ethiopia. Malar J 2009, 8:264.

14. Minakawa N, Dida GO, Sonye GO, Futami K, Kaneko S: Unforeseen misuses of bed nets in fishing villages along Lake Victoria. Malar J 2008, 7:165.

15. Pettifor A, Taylor E, Nku D, Duvall S, Tabala M, Meshnick S, Behets F: Bed net ownership, use and perceptions among women seeking antenatal care in Kinshasa, Democratic Republic of the Congo (DRC): opportunities for improved maternal and child health. BMC Public Health 2008, 8:331.

16. Becker-Dreps SI, Biddle AK, Pettifor A, Musuamba G, Imbie DN, Meshnick S, Behets F: Cost-effectiveness of adding bed net distribution for malaria prevention to antenatal services in Kinshasa, Democratic Republic of the Congo. Am J Trop Med Hyg 2009, 81:496-502.

17. Pettifor A, Taylor E, Nku D, Duvall S, Tabala M, Mwandagalirwa K, Meshnick S, Behets F: Free distribution of insecticide treated bed nets to pregnant women in Kinshasa: an effective way to achieve $80 \%$ use by women and their newborns. Trop Med Int Health 2009, 14:20-28.

18. Karch S, Asidi N, Manzambi ZM, Salaun JJ: The Anopheles fauna and the transmission of human malaria in Kinshasa (Zaire) (in French). Bull Soc Path Exot 1992, 85:304-309.

19. Zuur AELEN, Walker NJ, Saveliev AA, Smith GM: Mixed effects models and Extensions in Ecology with R. Springer 2009, 574.

20. Yohannes K, Dulhunty JM, Kourleoutov C, Manuopangai VT, Polyn MK, Parks WJ, Williams GM, Bryan JH: Malaria control in central Malaita, Solomon Islands. 1. The use of insecticide-impregnated bed nets. Acta Trop 2000, 75:173-183.

21. Ordinioha B: The use of insecticide-treated bed net in a semi-urban community in south-south, Nigeria. Niger J Med 2007, 16:223-226.

22. Alaii JA, van den Borne HW, Kachur SP, Shelley K, Mwenesi H, Vulule JM, Hawley WA, Nahlen BL, Phillips-Howard PA: Community reactions to the introduction of permethrin-treated bed nets for malaria control during a randomized controlled trial in western Kenya. Am J Trop Med Hyg 2003, 68(4 Suppl):128-136.

23. Noor AM, Omumbo JA, Amin AA, Zurovac D, Snow RW: Wealth, mother's education and physical access as determinants of retail sector net use in rural Kenya. Malar J 2006, 5:5.

24. Eisele TP, Keating J, Littrell M, Larsen D, Macintyre K: Assessment of insecticide-treated bednet use among children and pregnant women across 15 countries using standardized national surveys. Am J Trop Med Hyg 2009, 80:209-214.

25. Noor AM, Kirui VC, Brooker SJ, Snow RW: The use of insecticide treated nets by age: implications for universal coverage in Africa. BMC Public Health 2009, 9:369.

26. Noor AM, Moloney G, Borle M, Fegan GW, Shewchuk T, Snow RW: The use of mosquito nets and the prevalence of Plasmodium falciparum infection in rural South Central Somalia. PLoS One 2008, 3:e2081.

27. Toe LP, Skovmand O, Dabire KR, Diabate A, Diallo Y, Guiguemde TR, Doannio JM, Akogbeto M, Baldet T, Gruenais ME: Decreased motivation in the use of insecticide-treated nets in a malaria endemic area in Burkina Faso. Malar J 2009, 8:175.

doi:10.1186/1475-2875-9-279

Cite this article as: Ndjinga and Minakawa: The importance of education to increase the use of bed nets in villages outside of Kinshasa, Democratic Republic of the Congo. Malaria Journal 2010 9:279.

\section{Submit your next manuscript to BioMed Central and take full advantage of:}

- Convenient online submission

- Thorough peer review

- No space constraints or color figure charges

- Immediate publication on acceptance

- Inclusion in PubMed, CAS, Scopus and Google Scholar

- Research which is freely available for redistribution

Submit your manuscript at www.biomedcentral.com/submit 